\title{
Trials and Tribulations of Third World Petroleum Development: Lessons and Advice for Prospective Producers
}

\author{
HARRY G. BROADMAN* and ERNEST J. WILSON, III $\dagger$ \\ *Harvard University, 309 Belfer Center, Cambridge, Massachusetts 02138, and \\ $\dagger$ University of Michigan, Department of Political Science, Ann Arbor, Michigan \\ 48109-1220, USA
}

This paper presents a variety of lessons for governments of developing countries about how to begin to operate as new oil producers in the world petroleum market. Lessons, drawn from the recent experiences of currently producing LDCs, arc idcntified for each stage of the industry from exploration and development through procurcment and supply to refining and marketing.

\section{INTRODUCTION}

Unless we learn from the errors of the past we are doomed to repeat them. This is especially true in the international oil business, where every year billions $\left(10^{9}\right)$ of dollars hinge on correctly extrapolating from past trends to bet on the shape of the future.

While this is perfectly sound advice, to which particular facts from the broad storehouse of the petroleum past should attention be paid? Also, how can one learn about the workings of the world oil market when one has not had direct experience operating in it?

The need to discern lessons about the oil business is critically important for developing countries that possess petroleum resources but which lack much, or any, experience of exploiting them. The pronounced volatility in the price of oil, the radical shift in bargaining power between international oil companies and host governments, and the many choices of contract terms, taxation arrangements and sources of capital can present inexperienced developing countries' oil producers with a bewildering array of policy choices. How can such countries distil lessons about this industry's operations so separated by time, geography and vastly changing market conditions?

This paper outlines a variety of lessons about the operation of the world oil market for governments of developing countries that are new producers and those with strong prospects to become producers in the future. We structure our analysis of the problems posed by oil development in terms of the vertical organization of the petroleum industry (where wellhead activities constitute the extreme upstream stage and retail activities constitute the extreme downstream stage), rather than in terms of broad operational issues such as financial policies, legal frameworks, etc. Moreover, instead of concentrating on only one vertical stage we describe what to do, and

\footnotetext{
Dr Broadman, an economist, is a member of the faculty at Harvard University, Cambridge, Massachusetts and of the staff at Resources for the Future, Washington, DC.

Professor Wilson is co-author of The Decade of Energy Policy (Praeger), and has served as Special Advisor to the President of the Petroleum Finance Company. He teaches at the University of Michigan, and has consulted on energy for the World Bank and other private and public clients.
}

A version of this paper will appear in Petroleum Development Countries: Legal, Economic and Policy Issues, to be published by Belhaven Press, London.

Natural Resources Forum (C) United Nations, New York, 1987 
what not to do, for each major stage, from exploration and development, to procurement and supply and to refining and marketing.

The task we undertake is especially critical as the oil market moves into the late-1980s and early-1990s, which promise to be as risky and uncertain as the previous decade. ${ }^{1}$ The wide price and production swings, coupled with the emergence of both new factors and new transactional arrangements, means that in devising oil development strategies LDC government officials must be extremely circumspect, yet also bold and innovative. By circumspect we mean checking carefully the most promising options before acting; by bold, moving quickly and decisively once a strategy is selected; and by innovative, developing policies that not only respond to, but also anticipate, changes in the market. Moreover, because the past has been so tumultuous, earlier putative lessons are not necessarily applicable today. In other words, the relevant 'lessons' have changed as the structure of the market has changed and as the factors in the market have responded to such changes. In the current environment, financial as well as operational relationships are becoming increasingly complex. This is true in the interactions between the public and private sector factors, in general, and between the international oil companies (IOCs), LDC national oil companies (NOCs) and multilateral international organizations such as the World Bank, in particular.

Our analysis of many LDCs experiences leads us to one inescapable conclusion: a large number of countries have failed to capitalize on valuable market opportunities-in terms of expenditures as well as investments-because of poor policy choices. The result, in some cases, has been substantial losses - in both an 'out-of-pocket' and an 'opportunity cost' sense. The kind of review we provide here therefore has practical significance.

If there is a principal lesson we would stress it is that many, if not most, LDC NOCs-and their supervisory ministries- have not responded sufficiently quickly to the changing nature of the world oil market. Business practices and decisionmaking processes designed for an earlier time when the market was less competitive are now inefficient and costly. Moreover, no longer is the market highly vertically integrated and predictable.

Because of these changes it is necessary to derive lessons in the context of the petroleum industry as a whole. This 'all-industry' perspective is especially useful to LDC government decisionmakers for two reasons. First, LDC governments are typically responsible for monitoring domestic operations of the entire industry, even if they do not directly control or own any part of it. Second, one of the most important lessons of the $1970 \mathrm{~s}$ and early-1980s is that policy actions targeted at one level of the industry may have unintended and deleterious consequences for other levels. For example, price controls on sales at the refinery gate, imposed for political and social reasons, may retard upstream investment in exploration and development. Similarly, a regulatory strategy specific to exploration and development activities could well distort consumer welfare at the retail level. Thus, LDC governments need to be sensitive to the implications of their policies across all stages of the industry.

We should emphasize that in order to attain broad coverage of the most salient lessons yet also be concise we are unable to go into the technical, financial and other types of detail that could be presented with a more narrow focus. In a sense, then, we deliberately eschew an analysis of each tree to provide a road map through the forest. However, at the same time that we present a broad 'guidebook' of lessons, we recognize, and indeed insist, that in practice different national situations call for different strategies. Therefore, all of the lessons we outline must be carefully crafted and selectively applied to the concrete conditions in each country.

The core of this paper consists of four sections. The first three detail specific lessons for each of the three levels of the oil industry indentified above. Thus, we begin by addressing exploration and development issues, move on to procurement and supply, and then discuss refining and marketing. The fourth section covers institutional and management issues that are common to all of the industry's levels. We conclude the paper by concisely summarizing the most important lessons as a pragmatic guide for policy-makers. 


\section{EXPLORATION AND DEVELOPMENT}

It is widely agreed that there are relatively favourable geological prospects for the discovery of petroleum in a number of developing countries outside OPEC, including those that are currently producers. However, the pace of investment in exploration and development activities in many of these countries has been sluggish, especially compared with more-traditional areas such as North America and the Middle East, and with some frontier areas such as the North Sea. ${ }^{2}$ Several factors are responsible for this so-called 'drilling gap'.

First, some host governments are offering exploration and development contractual arrangements that, given the structure of investment payoffs in such projects, provide for an insufficient amount of financial risk-sharing with foreign investors (largely the IOCs), and this is deterring exploration. In short, some governments are shouldering too little of the risk. Economic theory indicates that investments involving parties that are risk-averse-a characteristic of both the typical LDC host government and IOC-should be governed by flexible institutional arrangements that provide for risk-sharing, with the allocation of risk based upon each party's ability to bear risk. Some host governments can bear more risk than is specified in the contracts they offer to foreign investors. All other things being equal, the level of foreign investment in exploration and development activity is likely to be enhanced where there is greater bearing of risk by government.

Certainly, because risk-bearing abilitics differ across LDCs (due, for example, to differences in the degree of each country's integration into international capital markets), a contractual arrangement that appropriately governs the allocation of the risks and rewards of exploration and development activity in one country may not do so in another. Thus, two countries that are equally promising geologically but have different capacities for bearing risk should probably offer different contractual arrangements to attract the same level of investment. There has been a substantial degree of uniformity in exploration and development contractual arrangements in many developing countries throughout the past 15 years, perhaps brought about by some sort of 'demonstration effect'. There is little question that this uniformity is an important reason why there has been a relatively low level of exploration and development investment in some of these areas.

Another set of factors that account for the relatively limited scope of exploration and development activity in LDCs concerns taxation. On one level the overall tax rate may be too high. However, there is an equally critical dimension of the relationship between taxation and exploration and development activity that needs to be taken into account: the structure of exploration and development tax rates across fields of varying size. It is well known that a progressive exploration and development tax structure-one in which tax rates rise with profitability-is an efficient taxation scheme because it does not impart a bias against exploiting small-volume, high-cost fields. Concisely, large, low-cost fields can support greater taxation than can small, high-cost fields. The latter type of field is likely to be the rule rather than the exception in most LDCs.

Unfortunately, progressive exploration and development tax systems have not been adopted by many of these countries. There are at least two reasons for this. First, they tend to shift economic risk to the host government, which (possibly myopically) may be reticent to assume greater risk. Second, such tax regimes may also be risky politically for the government because petroleum tax revenues-which often rouse national feclings-usually do not begin to accrue substantially under such systems until a project is well under way and profitability rises to a predetermined 'windfall' level.

However, other changes in exploration and development tax arrangements, such as differential royalties (for example, two-part or slidingscale tariff types of regimes), have been instituted and have made small, high-cost fields in some countries more attractive to investors. There is, though, evidence which suggests that even these modifications do not go far enough and that most exploration and development tax systems in LDCs still discriminate against exploiting highcost, small fields.

It should be noted that having argued that 
progressive exploration and development taxation schemes are generally the most efficient is not to suggest that all LDCs should adopt the same exploration and development tax system. Indeed, for the reasons alluded to above in the context of contractual arrangements, an exploration and development taxation scheme that is optimal for one country need not be optimal for another.

Several lessons are suggested by this analysis of exploration and development problems in LDCs. On one level there nceds to be a fundamental restructuring of exploration and development contractual and taxation terms for foreign investors. In particular, these provisions must be revised to provide for a more balanced allocation of the risk associated with the long-lived investments they govern. On another level, in light of the recent emergence of volatility in oil prices, which is likely to be a fundamental characteristic of the world oil market for the forseeable future, these provisions must also be revised to be more market-sensitive. Moreover, arrangements for smoother flows of information between the contractor and the government should be devised, including information about prices, market demand and the availability of supplies. Finally, LDC governments should recognize that IOCs present opportunities (as well as risks) and that a symbiotic (or a positive-sum game) approach will be mutually beneficial. ${ }^{3}$

\section{PROCUREMENT AND SUPPLY}

The most critical issues related to procurement and supply concern the mechanisms that firms and governments employ to obtain the supplies of crude oil or refined products needed to meet demand in the local market.

As is well known, most developing countries import all of their oil supplies. There are a few LDCs that produce petroleum but still import some percentage of their national requirements. A number of these producing-countries are like Zaire, which exports virtually its entire production because the domestic refinery is not designed to process the local grade of crude. Instead, Zaire imports crude that is compatible with its refinery. There are other LDC producers that are entirely crude-oil self-sufficient but must import a small percentage of refined products to satisfy special markets needs not easily met by the configuration of domestic refineries. Thus, for most developing countries, even those that are oil producers, it is necessary to master the procurement and supply process.

In one respect the procurement and supply area of the oil industry is often the most important economic activity in many developing countries. Imported oil generally constitutes the single largest item on the national import bill and hence is the largest user of foreign exchange. This means that by pursuing efficient procurement and supply strategies LDC governments can mitigate large outflows of foreign exchange.

The notion alluded to above that slow adaptation to changes in the world oil market has imposed costs on LDCs is seen most vividly in the case of procurement and supply. Many LDCs have been tied to procurement and supply import contracts that are not price-sensitive and hence do not reflect the fall in oil prices that has occurred in the past several years. Contracts written when prices were at US $\$ 35$ barrel $^{-1}$ continued even as spot-prices dropped below $\$ 30$. Also, when spot prices fell to $\$ 20$ and less, some countries were still paying contract prices of $\$ 27$ or $\$ 28$ barrel $^{-1}$. In addition, contract financing terms were often disadvantageous and did not reflect market changes, i.e. declines in interest rates.

A rough calculation of the difference between what could have been paid on the spot-market and what was actually paid under contract for crude and product imports for each of a variety of small, poor West African countries reveals a loss of almost $\$ 4$ million year ${ }^{-1}$. Such losses are not atypical for many LDCs.

What lessons can LDC governments learn from these experiences? In general, devising costeffective procurement and supply strategies is critical even for countries that have significant local production. Discovering and producing oil in commercial quantities should not become an opportunity to pay less attention to procurement and supply policics. Particularly in today's market, virtually all LDCs must strengthen their capacity in this area.

Let us be more specific. First, the importing government agency, usually the NOC, should avoid fixed-price contracts. While these are attractive when oil prices are rising, they are a terrible liability when prices are falling. Clearly, 
given the strength of oil price volatility, flexible contracts should be designed which use marketrelated pricing schemes that respond quickly to upward as well as downward trends in supply and demand. This will generally mean mastering knowledge of the spot-market and netback pricing schemes. In addition, it may also necessitate employing hedging techniques to insure against unexpected price movements.

Second, LDC governments must obtain more information on new, more-flexible financing techniques available from multilateral institutions like the World Bank, or from private banks. They must also learn how to maximize the advantages of using such instruments through moreaggressive bargaining with these lenders.

Finally, perhaps the most difficult lesson to put in practice: NOCs should try to devise pooled procurement and supply purchases, which can lever buying power and take advantage of economies of scale in the market. Most easily organized through regional buying schemes, neighbouring countries can call for bids from IOCs and then make the contract award to the lowest bidder. There have been some efforts along these lines among some island states in the South Pacific.

\section{REFINING AND MARKETING}

Downstream refining and marketing are critical components of a national petrolcum industry. Commercial success upstream in exploration and development does not change this important fact, it only complicates it. Indeed, we would warn governments of newly producing LDCs not to let the excitement of joining the ranks of oil producers blind them to the necessity of attentively managing downstream aspects of the industry.

An important part of the recent structural changes in the world oil market is that refining and marketing have become profit centres in their own right. ${ }^{4}$ Throughout most of the petroleum industry's history, crude operations have been the most important commercially; thus, the shift downstream is quite significant. Many companies, from the established 'majors' to newer enterprises like Kuwait Petroleum Co. (KPC), have adjusted their corporate strategies to this new reality. With respect to the 'majors', a number of them have developed or expanded greatly separate trading units, for example, Gulf's GOTCO. KPC, on the other hand, has developed an extensive refining and distribution network through aggressive acquisition of assets to achieve a high degree of vertical integration. This is not to suggest that NOCs from newly producing LDCs should pursue identical strategies; indeed, such strategies are likely to be beyond their financial and managerial capabilities, at least initially. Rather, the point is that in devising petroleum development plans governments of new producers need to pay as much attention to downstream activities as to upstream activities, perhaps in national and foreign markets. What are some specific lessons that can guide decision-makers in this regard?

\subsection{REFINING}

In the 1960 s a number of developing countriesproducers as well as non-producers-built refineries in order to gain some of the value-added being earned by the integrated international oil companies. These investments, which were most pronounced in West Africa and Southeast Asia, as well as in India and Brazil, allowed for the importation of cheap crude oil instead of moreexpensive refined products. The result was a significant savings in foreign exchange. Throughout the 1970 s many of these projects continued to be profitable, although in some cases, where domestic market changes produced a gap between the level and nature of end-use demand and the scale and process configuration of refineries, losses resulted. However, in today's market, with crude and product prices highly variable and with increasing reliance on netback pricing schemes, the profit margins on most of these investments have been reduced. As a result devising an appropriate refinery strategy has become more challenging. For the smallest and least efficient refineries, the least-cost option is perhaps obvious: simply dismantle the facilities and rely instead on the growing supplies of inexpensive product flowing out of the new export-oriented refineries in the Middle East. However, for other facilities, and thus more generally, what should be done? Essentially three options cxist: (a) build new (state-of-the art) refineries; (b) rationalize and upgrade existing facilities; or (c) mothball the facilities and temporarily meet demand through product imports. No single option, of course, is universally superior to the other two. Because each demand and 
supply situation is different from country to country, governments must embark on a refinery strategy that best meets local conditions. In some cases there is a great need for flexibility, so a mix of these options - where possible-is optimal.

We should note here an important implication of the changes in the structure of domestic demand that many LDCs have been experiencing in the past decade. Demand in most of these countries is shifting decisively toward middle distillates such as kerosene and automobile fuel. However, as refinery output is raised to increase the production of middle distillates, large amounts of fuel oil, for which there is insufficient domestic demand, are also produced. While the surplus is exported, because fuel oil typically is a low-value product, the overall profitability of refining operations is lower than it would be if the process configuration better matched the structure of demand.

NOC management, whose main task may be to operate the national refinery, is likely to balk at policies requiring refinery closure, and may well be unwilling to make the transition to function simply as a monitor of imports. Even if there is a recommendation to open up the domestic refining market to imports only partially, NOC management is likely to resist. However, government leaders should excrcise the willpower to insist that, at a minimum, the NOC should be subjected to competitive pressure. Experiences abound which demonstrate that exposing the national refining market to import competition helps to hold down consumer prices and reduces inefficiencies in NOC management.

All of these issues become technically and politically more complex with the advent of domestic production in the country. The more production there is, the greater the pressure to build or expand local refining capacity. The appropriate decision in this regard, however, can only be reached after analysis of the various options. At one extreme, for a country with relatively large production capacity and a relatively large domestic market, refinery construction probably makes sense. At the other extreme, for a country with low production and a small market, investment in refining may be unnecessary and therefore costly; instead, it may be more economical to export all of the crude and use the foreign exchange that is earned to finance product imports--as occurs, for example, in Zaire.

\subsection{MARKETING}

In terms of marketing (i.e. retail distribution of refined products to consumers and businesses), LDC governments today need to foster more market-sensitive pricing policies. Political and social pressures to subsidize rural populations often lead to a unified price scheme that does not accurately reflect marginal production and marketing costs. The central issue here is whether the gains in distributional equity outweigh the losses in efficiency.

Domestic oil prices worldwide have always been, and will probably continue to be, politically sensitive. This is especially true in developing countries, where governments have historically responded to local pressures to regulate or subsidize encrgy prices. LDC energy pricing policies typically incorporate cross-subsidization across fuels. For example, kerosene is frequently sold below market-clearing prices, while gasoline is usually taxed. Such schemes are designed with the objective of benefiting the poorest segments of society. However, because commercial energy use rises significantly with income, in the aggregate petroleum subsidies tend to benefit the middle class far more than the poor. Nevertheless, subsidization policies remain.

Indeed, the practice of politicizing retail petroleum prices is widespread in LDCs. This is especially true in countries with production. Consumers in these countries insist that oil is part of their national patrimony, that it is nearly free and, consequently, that its price should be heavily subsidized. Such arguments should be resisted by governments. In case after case it has been shown that artificially low downstream prices produce distortions in other segments of these countries' oil markets, and in their energy markets overall. They may also produce deleterious consequencies for macro-economic performance. For example, because artificially low oil prices increase local consumption, they lower the volume of petroleum available for export, and thereby depress potential export earnings.

We are aware of--indeed sympathetic to--the need for government to offset the negative effects of high energy prices on the poor. Given the 
distortions and ineffectiveness of subsidies, however, we prefer trying to accomplish this objective through lump-sum payments (either in cash or in kind) targeted directly at the groups in need.

\subsubsection{Overseas marketing: a special case}

Some new LDC producers may be blessed with petroleum resources that are larger than domestic demand. In these cases the question arises of what sales mechanism will maximize exports.

Throughout the history of the modern petroleum industry virtually all companies-both IOCs and NOCs alike-have sought innovative ways to market oil internationally. In the $1980 \mathrm{~s}$ the newest marketing institution in the crude-oil end of the business is netback pricing (used perhaps most effectively by Saudi Arabia). A netback price is the refined-product value of a barrel of crude less the processing and other costs. By shifting the price risk upstream, i.e. away from customers, and making price more responsive to changes in end-use demands, such a scheme allows producers to penetrate more effectively the international crude sales market. While netback pricing cannot (and should not) be practised by all producers - because the burden of shouldering price risk may be too costly for some countries-there is a general lesson here: some type of systematic market-based export pricing strategy needs to be devised by NOC management. No longer can oil sellers rely on buyers beating down the door. Prices must be set in a competitive fashion in order to attract premium buyers. This new marketing imperative is the other side of the coin of the new exploration and development imperative to design marketsensitive contractual and taxation schemes that were outlined above.

\section{INSTITUTIONAL AND MANAGEMENT ISSUES}

Institutional and management issues run through all three functional areas that we have analysed above. By institutional and management issues we mean the core activities associated with determining priorities, designing strategies and implementing policies that governments must perform. In this regard the operational lessons to be learned here are perhaps the most important.
We would like to draw attention to three major institutional and management concerns: (a) balancing NOC autonomy and control; (b) fostering competition in the domestic market; and (c) co-ordinating upstream and downstream activities.

\subsection{BALANCING NOC AUTONOMY AND CONTROL}

The lessons to be learned here are essentially those of all public enterprises, especially large parastatals that produce (or buy) goods traded in international markets. Perhaps the single most common feature shared by successful public enterprises is their autonomy from detailed and ex ante controls by civil servants in central ministries. NOCs which have exhibited strong economic performance and have made substantial contributions to national energy well-being tend to be those that have been given considerable authority by government to set (domestic and international) prices; to set terms for the hiring, firing and rewarding of personnel; and to determine investment priorities.

Another important lesson is that LDC NOCs at all levels of the industry must learn how to negotiate more efficiently with their privatesector suppliers, customers and, where present, thcir competitors. A common perception among NOC management who interact and negotiate with IOCs is that at every turn the IOCs try to keep the government in the dark. Clearly, the history of the international oil industry offers numerous examples of IOCs trying to hoodwink LDC governments, or worse. At the same time interviews with industry officials, and the confidential records of others, indicate that one of the most frequently voiced complaints that lead IOCs to consider very carefully whether to invest (or reinvest) in an $\mathrm{LDC}$ is whether the NOC officials in that country are seen as knowledgeable, competent and enjoy the confidence of government leaders. If they do not, the worry is that a contract negotiated on very favourable terms may be abrogated in mid-stream when a new official comes on board. ${ }^{5}$

Financial autonomy is the area where many of these issues are most clearly seen. In some countries the national oil company has its hands tied because it is subject to the same bureaucratic regulation as other public enterprises; yet the 
NOC's needs are quite different given the strategic position of oil in the economy. For example, the government may set spending limits on the NOC's expenditures; it also may require several levels of ministerial officials to sign off on an NOC contract. In one instance that we observed, a procurement and supply import contract was almost lost because the chairman of the central bank was out of the country and only he could sign off on the $\$ 25$ million payment. The obvious lesson here is that governments must give their NOCs a sufficient degree of autonomy. Government should set the general priorities and guidelines, but it should stay out of the NOC's daily operational issues; it will attain sufficient influence in that sphere through its power on the board of directors and by exercising its authority to name top management.

\subsection{FOSTERING COMPETITIVENESS}

The standard remedy for poor NOC performance was once routinely given as 'more autonomy'. However, as more evidence has become available, it turns out that more autonomy is only half of the cure; the other half is 'more competition'. Government needs to devise policies that provide NOCs with autonomy but also foster competitiveness in their pricing and investment decisions. ${ }^{6}$

It is well known that in strategic sectors like oil, governments worldwide have often been reluctant to permit much competition. This has been especially true in smaller countries with pronounced national security concerns. Of course, in most LDCs the inability (or unwillingness) to rely on the 'invisible hands' and thus the use of protectionist measures pertains to other, non-oil sectors as well. In oil, many LDC governments fear the long arm of the IOCs or the threatening touch of local businessmen, and are loath to permit competition with the NOC. Nevertheless, in case after case the evidence suggests that by subjecting NOCs to competitive pressure economic welfare is greatly enhanced. This is as true in the downstream portion of LDCs' oil sectors as it is in the upstream portion.

\subsection{Co-ORdiNATION STRATEgIES}

Throughout this paper we have stressed the importance of the interconnectedness of the various levels that comprise an LCD's oil sector.
We have also alluded to the importance of the interconnectedness between oil and other energy sectors. In these two regards several lessons should be noted.

To take the second aspect first, LDC governments should develop policies that promote competition between oil and other fuels. This usually requires eliminating subsidies on particular fuels and allowing-indeed fostering-the configuration of relative prices to match marginal social costs. Certainly, achicving distributional equity is just as important as achieving efficient pricing. However, as was argued above, meeting the equity objective is often better addressed using policy instruments outside the price system per $s e$. With socially efficient pricing policies in place, cnergy demand will be more elastic and the prospects for interfuel substitution will be enhanced. This means that the typical LDC economy will be more resilient to the price shocks that have become the hallmark of the world oil market. In addition, it will mean increased incentives for investment in conservation projects, both in households and in industry.

There are two major points that should be made regarding the interrelationships among the oil sector's stages. One concerns the optimal level of government involvement in each stage. Whether such involvement occurs through state ownership or regulatory oversight, it is often less justified in exploration and development, refining and retailing activities than it is in the transport and distribution stages, where market failure, (i.e. natural monopoly) arises because of inherent technological factors. The other issue concerns government policies that maximize the efficiencies of integrating upstream and downstream activities. The role of government here is to promote vertical integration up the point where the economies of joint ownership of successive stages of production (e.g. refining and pipelining) are just exhausted. This will enchance the ability of price signals to be efficiently transmitted between points of consumption and production, and thus balance upstream supply with downstream demand.

\section{CONCLUSION}

In the foregoing we have raised many issues that LDC governments should consider in devising 
their petroleum development strategies. The principal lessons that emerge from our analysis can be summarized in the following way.

\section{Exploration and development}

- Host governments should lessen onerous contractual and fiscal terms for foreign investors (i.e. IOCs), and make them more flexible.

- Financial provisions should be devised which yicld a more efficient allocation of risks.

- Arrangements for smoother flows of information between NOCs and IOCs should be devised, including information about prices, supply and demand, and transfers of technology.

- Host governments should recognize that IOCs present opportunitics not just risks, and that a symbiotic (or a positive-sum game) approach will be most beneficial to all parties.

Procurement and supply

- NOCs should avoid fixed-price contracts.

- Use market-related pricing schemes, e.g. netback provisions.

- Adopt hedging techniques, i.c. learn how to use the spot and future markets.

- Take advantage of new financing opportunities from both private and public sources.

- Devise pooled transactional arrangements, e.g. sellers' or buyers' co-operatives.
Refining and marketing

- Do not overbuild; LDC governments should consider carefully the 'buy versus build' tradeoff.

- Do not overemploy.

- Maintain flexible refining capabilities in light of the increased volatility in both supply and demand of crudes/products of various qualities.

- Permit greater competition from imports in order to hold down ex-refinery prices.

- Facilitate efficient and price-sensitive distribution networks.

\section{Institutional and management issues}

- LDC governments should provide for increased opcrating autonomy of their NOCs; specifically, in decisions regarding capital investment, pricing, personnel and negotiations (with IOCs).

- Improve NOCs capital structure (i.e. debtequity ratio) in order to attract financing more cheaply.

- Government should encourage competition in each segment of the country's petroleum industry, including the elimination of sanctioned monopolies.

- Devise policies to co-ordinate upstream and downstream sectors; e.g. develop integration strategies.

\section{NOTES}

1. For a general discussion of the turbulence in the world oil market see Wilson, E.J., III, 1986. The Petro-Political Cycle in World Oil Markets 1970-1985. In: Ender, R. and Kim, J., Natural Resource and Energy Policy, Kenikat Prcss.

2. See Broadman, H.G., 1985. Incentives and Constraints on Exploratory Drilling for Petroleum in Developing Countries. A. Rev. Energy 10.

3. Further analysis along these lines is contained in Broadman, H.G. and Dunkerley, J., 1985. The Drilling Gap in Non-OPEC Developing Countries: The Role of Contractual and Fiscal Arrangements. Nat. Resour. J. 25 (3).

4. See Kemezis, P. and Wilson. E.J., III, 1984. The Decade of Energy Policy: Policy Analysis in Oil Importing Countries. Praeger, New York.

5. See Wilson, E.J., III, (forthcoming) World Politics and International Energy Markets, in International Organization.

6. See Broadman, H.G., 1985. Oil Exploration in Developing Countries. Energy Policy, 13 (4). 